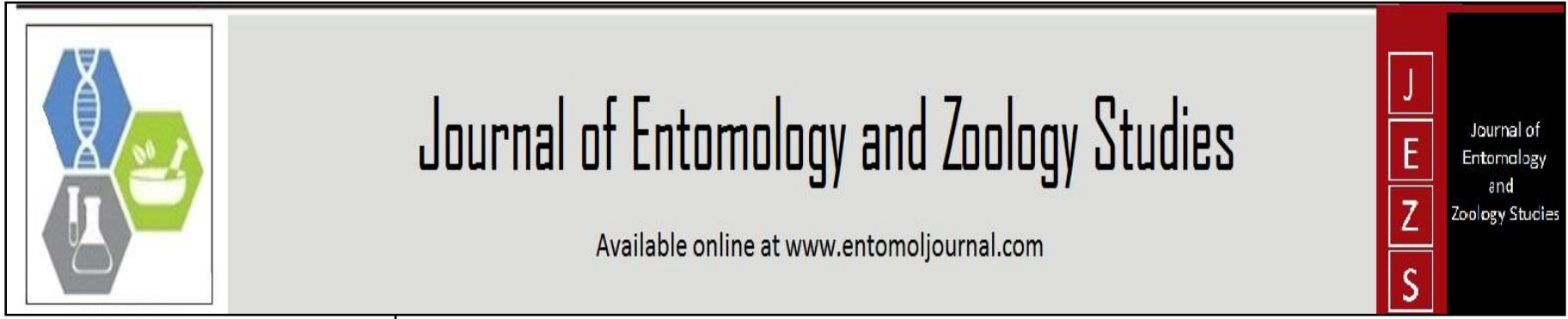

E-ISSN: 2320-7078

P-ISSN: 2349-6800

www.entomoljournal.com

JEZS 2021; 9(3): 398-403

(C) 2021 JEZS

Received: 10-03-2021

Accepted: 12-04-2021

\section{Omveer Dhawal}

Sarisha Wildlife and Ecology

Society (WNE), Sarisha,

Nabasan Road, West Bengal,

India

\section{Arnab Sarka}

Department of Zoology, City

College, 102/1, Raja Rammohan

Sarani, Kolkata, West Bengal,

India

\section{Vivek Sharma}

Biodiversity Research

Laboratory, Department of

Zoology, Maharshi Dayanand

Saraswati University, Ajmer,

Rajasthan, India

\section{Shwetadri Bhandari}

Sarisha Wildlife and Ecology

Society (WNE), Sarisha,

Nabasan Road, West Bengal,

India

\section{Puja Ray}

Multitrophic Interaction and Biocontrol Research Laboratory, Department of Life Science, Presidency University, Kolkata, West Bengal, India

\section{Corresponding Author:}

\section{Puja Ray}

Multitrophic Interaction and

Biocontrol Research Laboratory,

Department of Life Science,

Presidency University, Kolkata,

West Bengal, India

\section{Diversity of Snakes in and around Jawai Dam, Rajasthan, India}

\author{
Omveer Dhawal, Arnab Sarkar, Vivek Sharma, Shwetadri Bhandari and \\ Puja Ray
}

DOI: $\underline{\text { https://doi.org/10.22271/j.ento.2021.v9.i3f.8736 }}$

\section{Abstract}

Snakes are speedily declining around the world due to human mediated habitat loss and global environmental changes. Hence constant monitoring of their diversity and well being is necessary. During the present study under our Sarpa Sathi project, we surveyed for snake diversity using time-constrained search, incidental encounters around the Jawai Dam, Sumerpur, Pali, Rajasthan, India, for the first time. The area has been insufficiently documented in terms of biodiversity. During a study period of three years we identified a total of 23 species of snakes, belonging to 20 genera and 7 families. Among these Colubridae was the most abundant family with 12 representative species. 5 species are highly venomous and has been known for causing fatality in humans. 3 species are mildly venomous and has no known record of human casualty. Remaining 15 species are all non-venomous. The study indicate a decent diversity of snakes in the region and highlight on need for increased efforts towards conservation of these important members of food web.

Keywords: Biodiversity, habitat loss, Jawai Dam, ophiofauna, snake

\section{Introduction}

Reptiles in India, especially snakes, remain less studied and often misunderstood. Although herpetological study in India goes way back in 1790s (Russell, 1796) ${ }^{[5]}$, they were fairly rudimentary. Proper scientific studies on Indian reptiles started around 1930s (Smith, 1931, $1935,1943)^{[7-9]}$. The work of Smith forms the standard on the subject. In the $21^{\text {st }}$ century, (Das, 2003), compile the checklist of Indian reptiles and amassed a benchmark reference work on the subject.

Though the reptile fauna of whole India is well documented in studies mentioned above, there was no consolidated faunistic work on Rajasthan reptiles in particular. In 1970s, pioneering study on this regard was done by Biswas (1977) ${ }^{[6]}$, providing a standard checklist of reptiles of Rajasthan. Over the years specially in the last two decades quite a few studies on herpetofauna has been conducted in Rajasthan, mainly around Thar desert and adjoining areas. The work of Das and Rathore (2004) ${ }^{[2]}$ give us a general idea about the subject, which is further consolidated by the work of Gala and Khandal (2010) ${ }^{[3]}$. Although the above mentioned studies provide us with a basic understanding, none of these focuses solely on snakes. With increasing habitat modification and climate change it is essential to continuously monitor biodiversity. Thus our work during the ongoing project, Sarpa Sathi is aimed to provide a solid data about ophiofauna of Jawai Dam and surrounding areas, which has never been properly studied before.

\section{Materials and Methods}

Study Area: The study area encompasses sixteen villages (Bisalpur, Jawai Bandh, Balwana, Sumerpure, Doodni, Varaval, Mori Bera, Bhatund, Sena, Jeewada, Bera, Perwa, Koliwara, Kothar, Bijapur and Jakhora) surrounding the area of Jawai Dam, Sumerpur, Pali, Rajasthan, India. The dam is built across the Jawai river. The dam and the surroundings cover an area of 500 sq.km, making it the largest dam in the western Rajasthan. The study site lies around $25.1170^{\circ} \mathrm{N}$ and $73.1438^{\circ} \mathrm{E}$ at an elevation of approximately $61.25 \mathrm{ft}$ or $18.67 \mathrm{~m}$. The dominant natural climax vegetation of the study site is dry deciduous forest. Apart from this, some patches of dry deciduous scrub or desert dune scrub are present (Reddy, 2011). 


\section{Field studies}

The work is based on periodical field visits between 2018 to 2021. We employed time constrained search and random active searches both during day and night to get the most accurate results. The same procedure was followed across all seasons in order to find as many samples as possible. During the search, possible micro habitats were examined carefully; such as underneath of logs and rocks, leaf litters, burrows near water bodies, tree holes. Incidental encounters, road kill reports, dead specimens received from locals were also considered. Accidental encounters with individuals, in case of rescue calls were also taken into account while compiling the checklist. Sighted individuals were examined and photographed before releasing them in the same habitat where observed. No specimen is preserved; rather the records are supported by photographic evidences.

\section{Results}

During our study, we identified a total of 23 species of snakes (Table 1), belonging to 20 genera and 7 families (Fig 1, 2, 3, 4). Among these 12 species belong to the Colubridae, making it the most abundant family of the region.

Out of the 23 identified species, 5 species are highly venomous and has been known for causing fatality in humans. 3 species are mildly venomous and has no known record of human casualty. Remaining 15 species are all non-venomous (Fig 5). Incidentally, Naja naja, Bungarus caeruleus, Daboia russelii, Echis carinatus; all four of these species, commonly known as 'Big four' (Whitaker and Martin, 2015) ${ }^{[12]}$, were found during the study.
Three species including Amphiesma stolatum, Ahaetulla nasuta, Bungarus sindanus; do not have photographic evidence but are placed on the list based on sighting records available in past literatures. Two species Amphiesma stolatum and Ahaetulla nasuta were well documented and are commonly found in Rajasthan, barring the north western part of the state (Whitaker and Captain, 2004) ${ }^{[11]}$. In case of Bungarus sindanus, although it is not as well documented as the other two, but recent studies (Whitaker and Martin, 2015) ${ }^{[12]}$, confirmed its presence throughout the Rajasthan state.

Out of 23 identified species of snakes, 11 species (Ramphotyphlops braminus, Python molurus, Eryx johnii, Coelognathus Helena, Ptyas mucosa, Platyceps ventromaculatus, Lycodon aulicus, Xenochrophis piscater, Boiga trigonata, Bungarus caeruleus, Naja naja) were very common in the study area and has been observed in all of the 16 villages often during our field survey. Notably, Naja naja and Bungarus caeruleus are very commonly found.

Four species, Gongylophis conicus, Oligodon arnensis, Lycodon otriatu, Echis carinatus were slightly less observed during the field work yet have been observed in most of the villages.

Three species, Grypotyphlops acutus, Oligodon taeniolatus, Amphiesma stolatum are less common in the study area. Grypotyphlops acutus has been recorded only from the village Bisalpur thrice. Oligodon taeniolatus was observed in three villages, Bisalpur, Jawai Bandh and Sumerpure. Five species, Spalerosophis atriceps, Ahaetulla nasuta, Psammophis leithii, Bungarus sindanus, Daboia russeli are very rarely found inside the study area.

Table 1: Checklist of snakes species observed during the study.

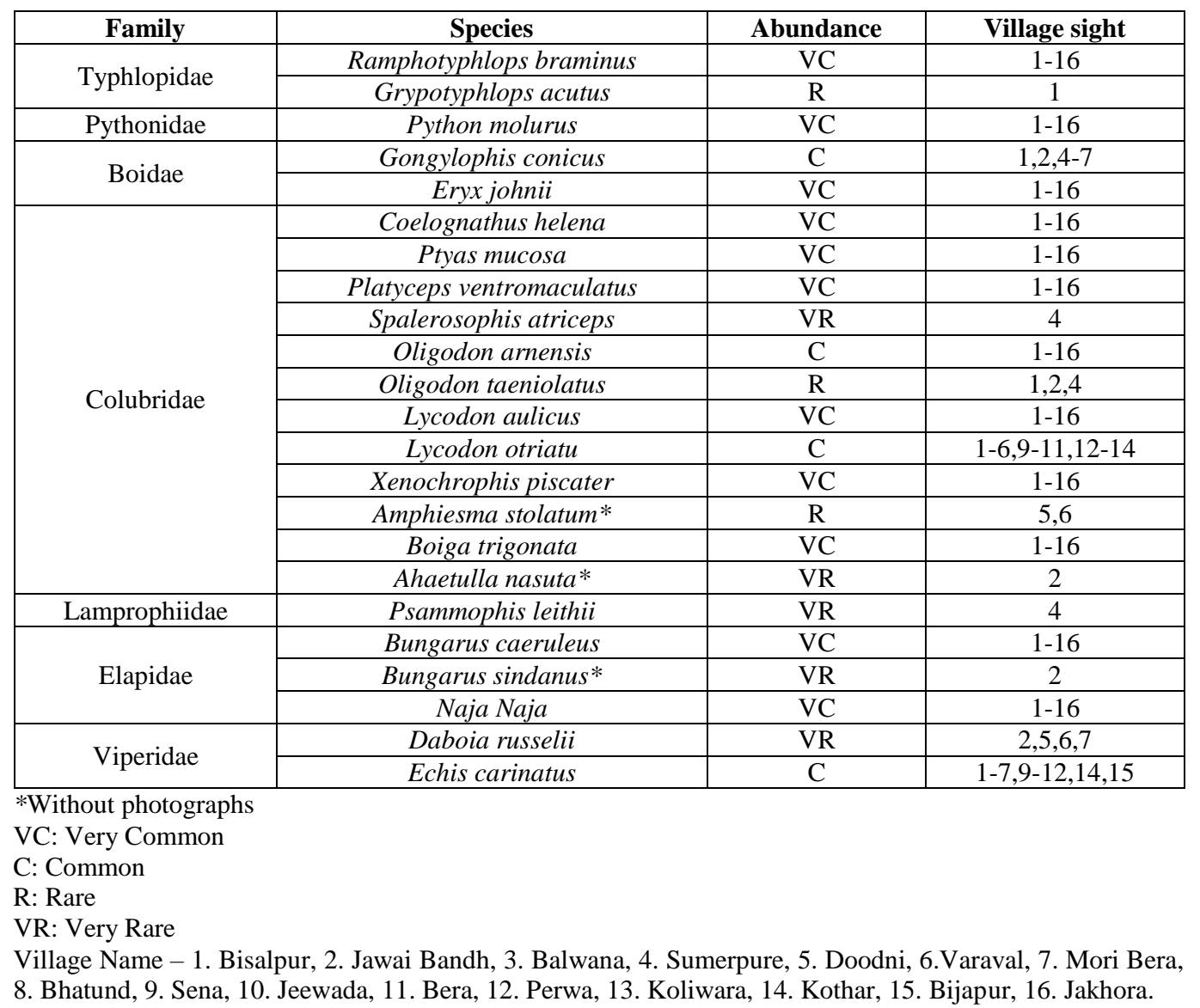



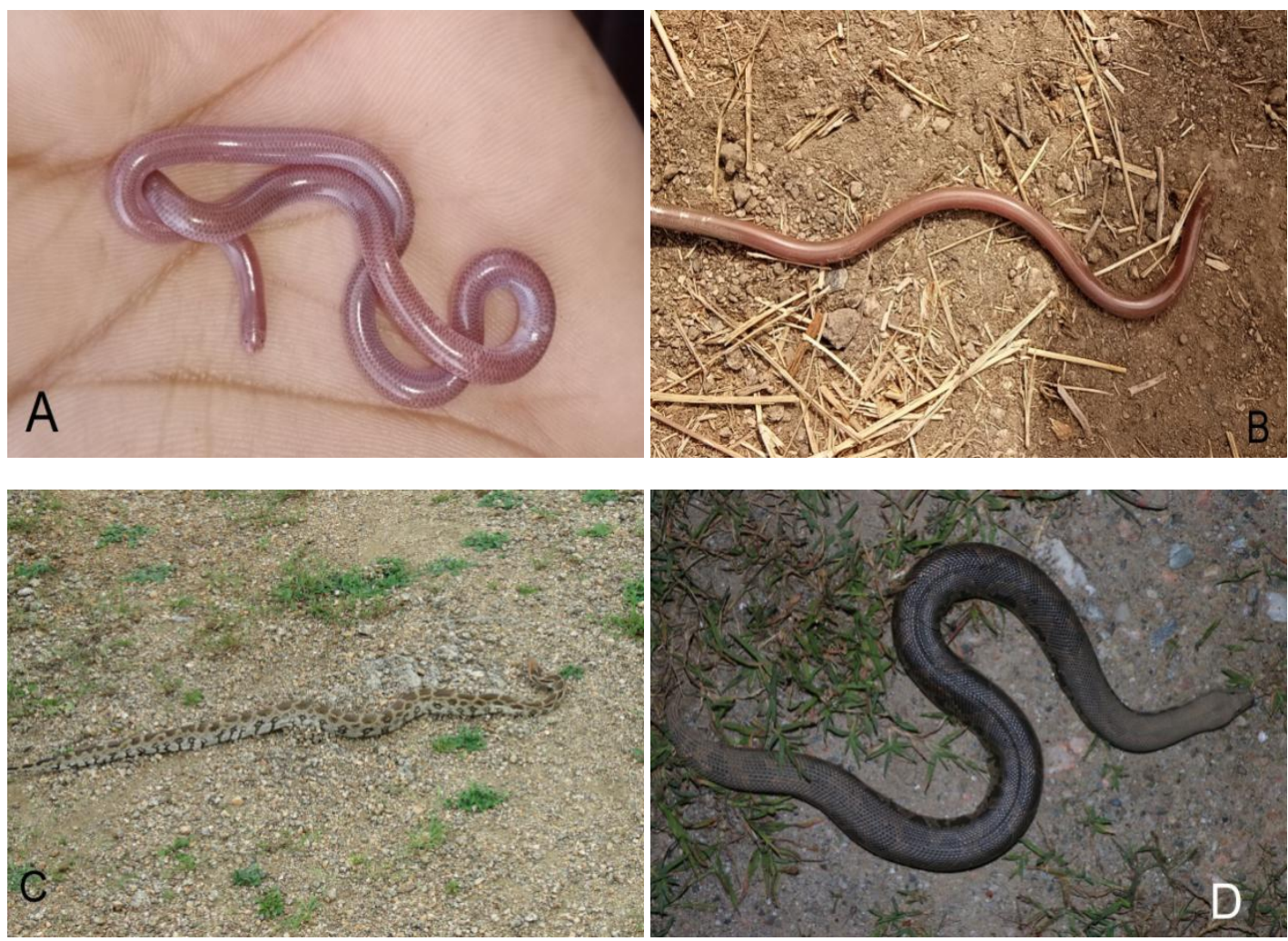

Fig 1: Diversity of snake species at Jawai, Rajasthan: A- Ramphotyphlops braminus, B- Grypotyphlops acutus C- Python molurus, DGongylophis conicus
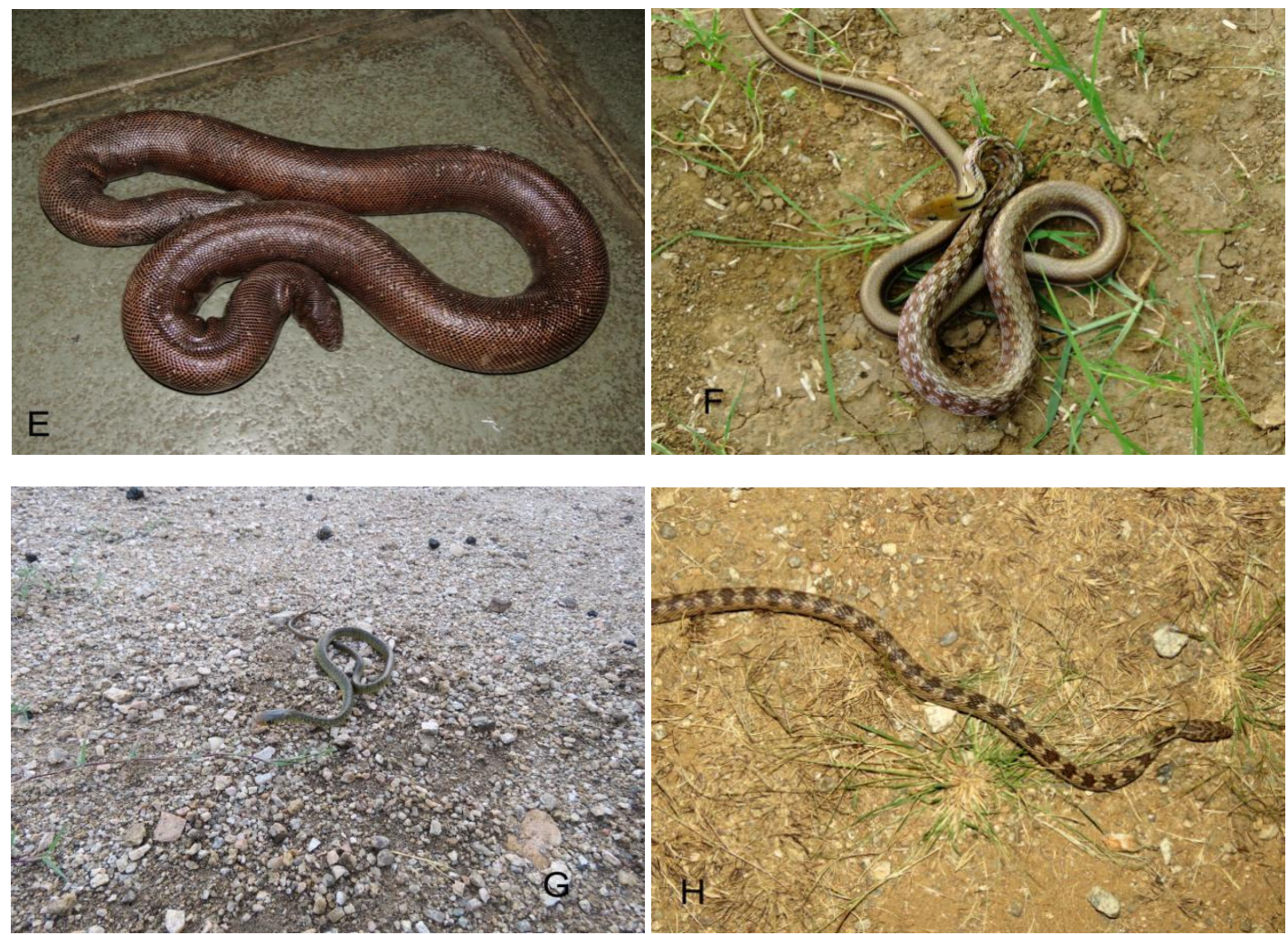

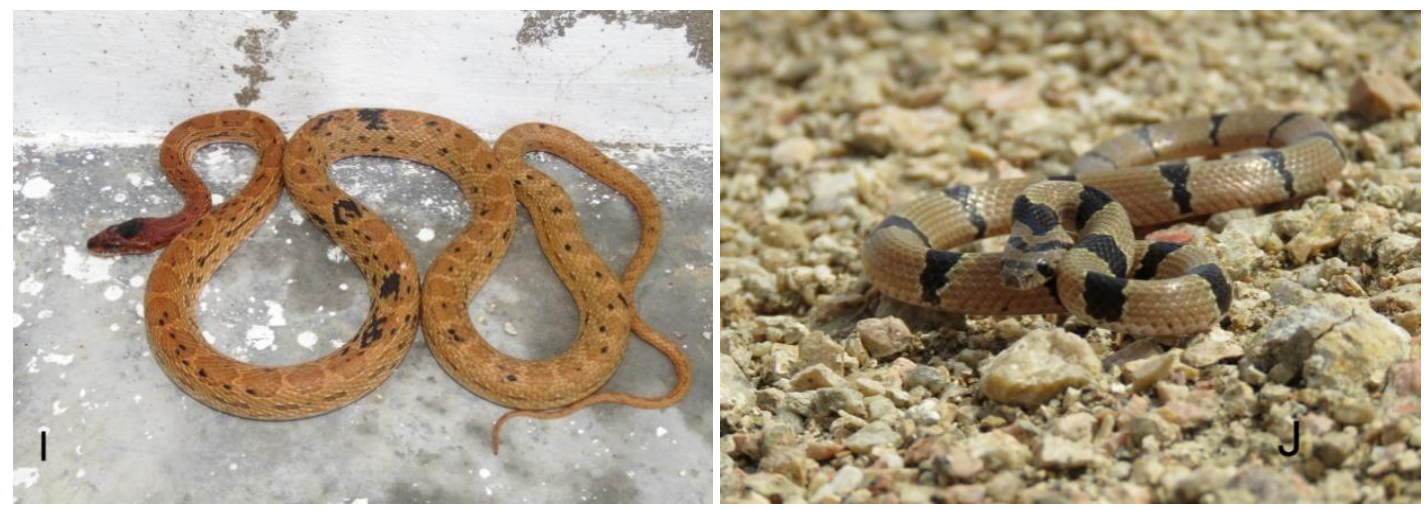

Fig 2: Diversity of snake species at Jawai, Rajasthan: E- Eryx johnii, F- Coelognathus helena, G- Ptyas mucosa,H- Platyceps ventromaculatus, I- Spalerosophis atriceps, J- Oligodon arnensi
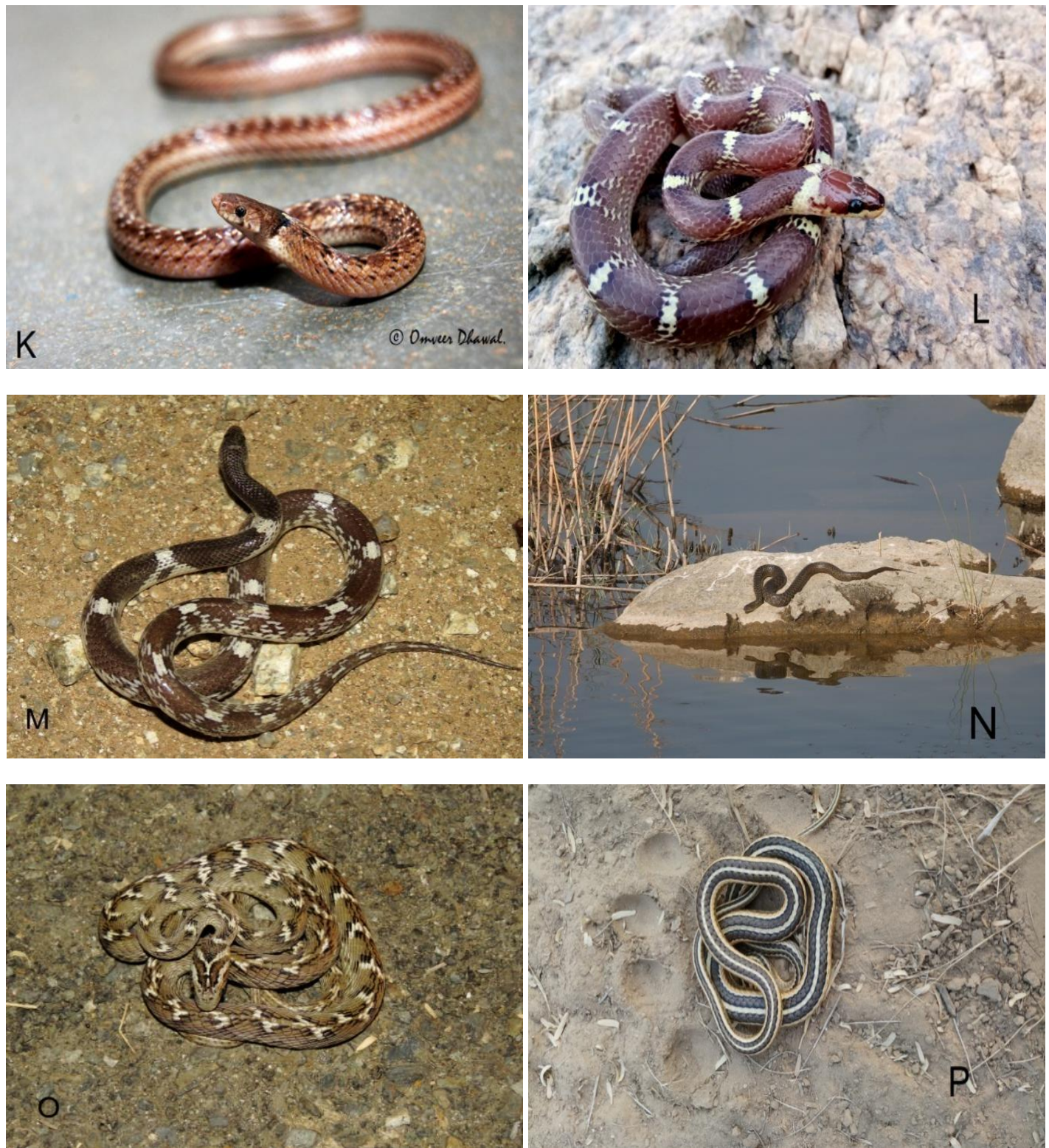

Fig 3: Diversity of snake species at Jawai, Rajasthan: K- Oligodon taeniolatus, L- Lycodon aulicus, M- Lycodon otriatu, N- Xenochrophis piscater, O- Boiga Trigonata, P- Psammophis leithii 

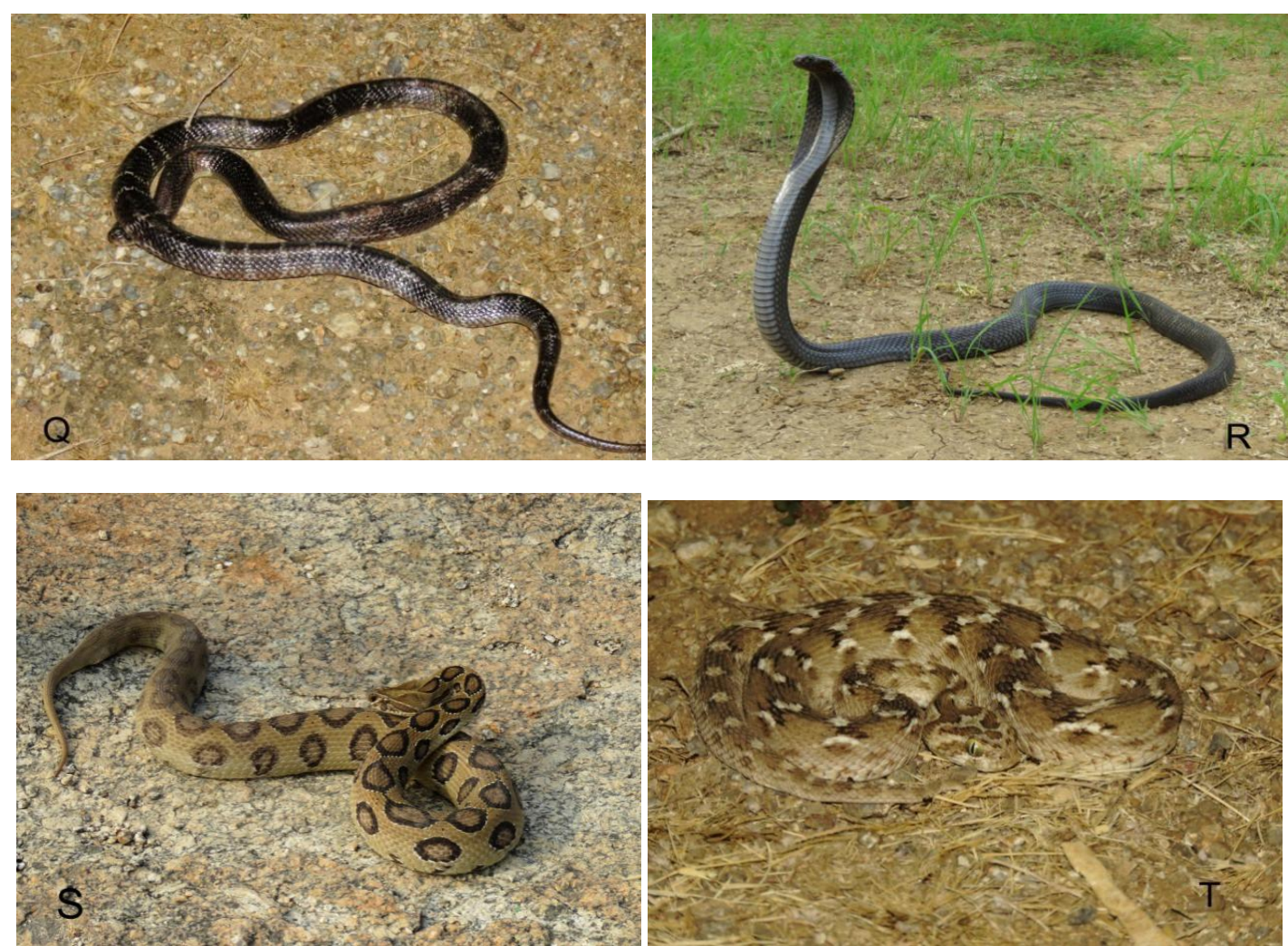

Fig 4: Diversity of snake species at Jawai, Rajasthan: Q- Bungarus caeruleus, R- Naja Naja, S- Daboia russelii, T- Echis carinatus.
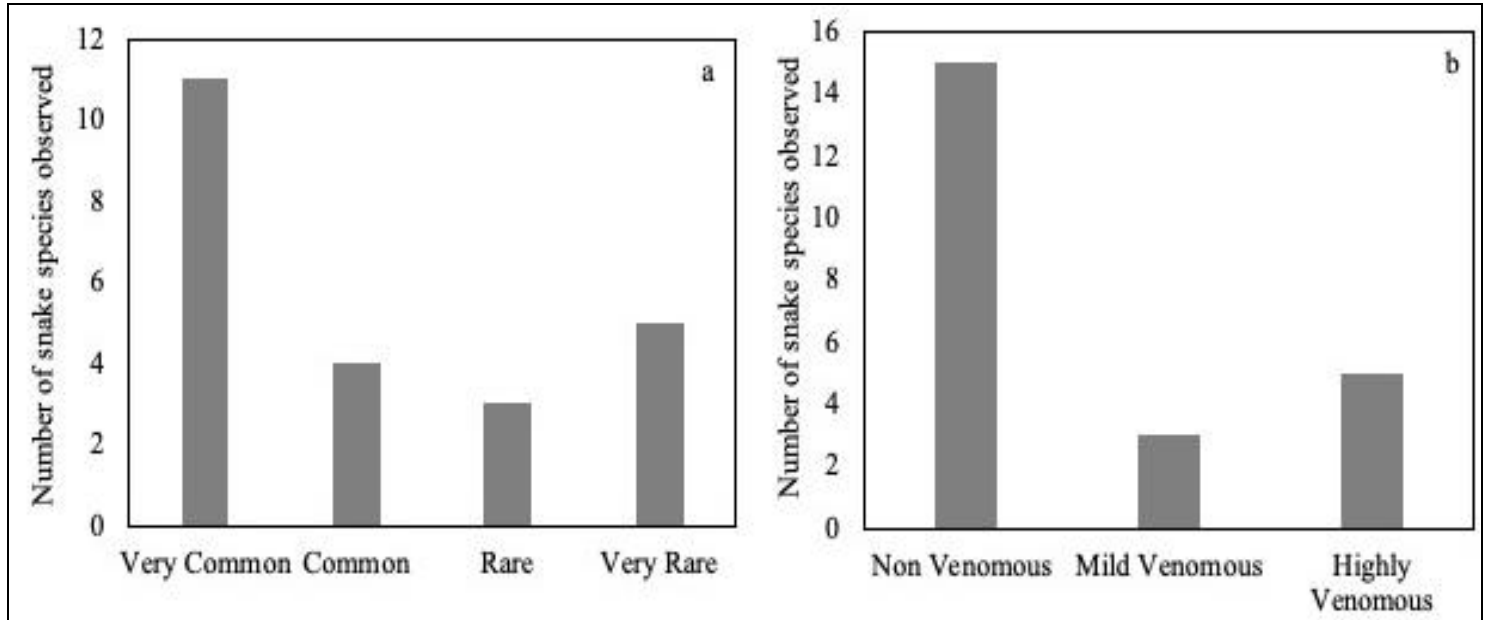

Fig 5: Number of species of snake (a)as per abundance (b)as per their venom

\section{Discussion}

There is a rich ophiofaunal diversity at Jawai, Rajasthan. For the rarely observed species, there is a possibility that population of these species may be rapidly declining. However in absence of earlier data it is difficult to ascertain the extent of the issue. Thus long term studies are warranted to safeguard the existing biodiversity. According to our estimates Jawai Dam and the surrounding area supports a rich diversity of snakes, possibly, much more than observed during the project duration. There is an increasing loss of biodiversity including the snake diversity as a result of global environmental changes including human mediated habitat loss and climate change (Pimm 2008) ${ }^{[4]}$. Thus there is a dire need to be properly studied in order to come up with a plan not only to conserve the species and their habitats but also to reduce human-snake conflict by spreading awareness. Further there is also a dire need for methods of improved forecasts and modelling for enhancing conservation efforts for the snake diversity of the region.

\section{Acknowledgement}

The authors are thankful to the Forest Department of Jawai for necessary support and permissions for this study. The authors wish to acknowledge locals snake rescuers of Jawai, Ashok Soni, Dilip Solanki, Uttam Chouhan, Naresh Vaishnav, Kuldeep Mewara, Suddam Husain for their help during the study. Special thanks are due to Rakesh Kumawat for helping in study and motivation.

\section{References}

1. Das I. Growth of Knowledge on the Reptiles of India, with An Introduction To Systematics, Taxonomy and Nomenclature. The Journal of the Bombay Natural History Society 2003;100:446-501.

2. Das S, Rathore N. Fauna of protected areas - 13: herpetofauna of Desert National Park, Rajasthan, India. 
Zoos' Print Journal 2004;19(9):1626-1627.

3. Gala M, Khandal D. A rapid survey of squamate reptiles in the Thar Desert of Rajasthan, India. Cobra (Chennai), e 2010;4(1):28-39.

4. Pimm SL. Biodiversity: Climate change or habitat lossWhich will kill more species? Current Biology 2008;18(2):R117-9.

5. Russell P. An Account of Indian Serpents Collected on the Coast of Coromandel; and Remarks on their Several Poisons. George Nicol, London 1796; viii + 90 + pls. I.

6. Biswas S, Sanyal DP. Fauna of Rajasthan, India, Part. Reptilia. Records of the Zoological Survey of India. 1977;73:247-269.

7. Smith M. The fauna of British India including Ceylon and Burma: Reptilia and Amphibia. Volume I. Taylor and Francis London UK. 1931; xxvii+ 185+2pl.

8. Smith M. The fauna of British India including Ceylon and Burma: Reptilia and Amphibia. Volume II. Taylor and Francis London UK. 1935; xiii+440pp+1pl

9. Smith M. The fauna of British India including Ceylon and Burma: Reptilia and Amphibia. Volume III. Taylor and Francis London UK 1943;xii+583pp+1 map

10. Sudhakar Reddy C, Hari Krishna P. Mapping the vegetation types of Rajasthan, India. Journal of Environmental Research and Management 2011;2(1):001-009.

11. Whitaker R, Captain A. Snakes of India: The Field Guide. Chennai, India: Draco Books 2004.

12. Whitaker RE, Martin G. Diversity and Distribution of the Medically Important Snakes of India. Clinical Toxinology in Asia Pacific and Africa 2015, 115-136. 